\title{
Diseño de imágenes para piezas inmersivas utilizando el método de pantallas nulas dentro de la región de la cáustica
}

\author{
E. G. Vázquez-Navarrete \\ Facultad de Artes y Diseño, Universidad Nacional Autónoma de México, \\ Cto. de los Posgrados S/N, Edif. A. PB. C.U., 04510 Ciudad de México, CDMX. \\ e-mail: edith.vazquez.n@gmail.com \\ G. Castillo-Santiago \\ Instituto de Ciencias Aplicadas y Tecnología, Universidad Nacional Autónoma de México. \\ 04510, Apartado Postal 70-186, Cd., México \\ M. Avendaño-Alejo \\ Instituto de Ciencias Aplicadas y Tecnología, Universidad Nacional Autónoma de México. \\ 04510, Apartado Postal 70-186, Cd., México.
}

Received 18 August 2019; accepted 9 January 2020

\begin{abstract}
El diseño de patrones predefinidos está ejecutado con procesamiento de imágenes a partir de un retrato fotográfico, con el cual hemos implementado el método de pantallas nulas por refracción para la creación de piezas de arte inmersivas, que implica un espacio donde el público se sumerge en una experiencia visual envolvente de 360 grados. En este trabajo se supone la incidencia de un frente de onda plano en una lente asférica plano-convexa. Con el conocimiento del trazo exacto de rayos y la forma de la cáustica, se calcula la posición para colocar un detector CCD donde la intensidad es uniforme y podemos reconstruir el retrato en forma de patrón predefinido. Las imágenes fueron registradas en tiempo real y pueden ser proyectadas en medios digitales desde el montaje experimental. Como resultado final se obtuvo la visualización reconfigurada de un retrato fotográfico a partir de su pantalla nula por refracción y se concluye que la estética de los resultados pueden ser funcionales para su aplicación en piezas de arte inmersivas.
\end{abstract}

Descriptores: Artes visuales; obras inmersivas; retratos; óptica geométrica; cáusticas.

The design of predefined patterns is executed with image processing from a photographic portrait, with which we have implemented the null screen test by refraction in order to create immersive art pieces, which implies a space where the public is immersed in a 360 degree surround visual experience. We assume the incidence of a plane wavefront on a plano-convex aspheric lens. With the knowledge of the exact ray tracing and the caustic, we calculate a position where the CCD detector is placed and irradiance is uniform and we can reconstruct the portrait in the form of a predefined pattern. The images were recorded in real-time and can be projected on digital media from the experimental setup directly. As a final result, the reconfigured visualization of a photographic portrait was obtained from its null screen by refraction and it is concluded that the aesthetics of the results can be functional for application in immersive pieces of art.

Keywords: Visual arts; immersive works; portraits; geometric optics; cacoustics.

PACS: 42.15.-i.

\section{Introducción}

El diseño de imágenes predefinidas utilizando el método de pantallas nulas por refracción, con una particular aplicación en piezas de arte inmersivas, surge en el contexto de una investigación multidisciplinaria donde confluyen arte, ciencia y tecnología. Se plantea establecer una nueva metodología para producir imágenes en el terreno del arte.

Los principios de reflexión y refracción de la luz han sido extensamente estudiados a la largo de la historia de la óptica. El desarrollo teórico funcional de estos fenómenos sigue en constante evolución y se han desarrollado numerosos procedimientos para describir adecuadamente la propagación de los rayos y frentes de onda, ya sea reflejados o refractados a través de sistemas ópticos arbitrarios. La superficie cáustica puede definirse como el lugar geométrico de los centros de curvatura de la familia de frentes de onda refractados o reflejados. También es la envolvente de los rayos refractados
DOI: https://doi.org/10.31349/SuplRevMexFis.1.25

o reflejados por un sistema óptico [1] y juega un papel fundamental en la formación de imágenes. En las Refs. [2-8] se puede observar que han sido publicados un número importante de investigaciones sobre cáusticas por refracción, también denominadas diacáusticas.

Las lentes asféricas tienen usualmente sólo una cara asférica, que es modificada de una esfera u cónica con el fin de reducir aberraciones [9], aunado a ello, pueden ayudar a simplificar el diseño de sistemas ópticos al reducir la cantidad de elementos requeridos, y producen imágenes más nítidas que las lentes convencionales. Los elementos asféricos son particularmente útiles para corregir la distorsión en lentes de gran angular. En resumen, las superficies ópticas asféricas ofrecen sistemas de mayor rendimiento, son más compactos y más ligeros para ser utilizados en una amplia gama de diversas aplicaciones.

En metrología óptica, las pruebas de Ronchi y Hartmann 
han sido tema de investigación durante muchos años, ya que permiten evaluar de manera eficiente superficies ópticas cóncavas y convexas de pequeñas y grandes dimensiones. En el caso de la prueba de Ronchi, se utiliza una rejilla de franjas claras y obscuras igualmente espaciadas en el plano de detección y la fuente de iluminación se coloca cerca del radio de curvatura para evaluar espejos cóncavos. En la prueba de Hartmann se utiliza una pantalla u obstrucción de orificios que se coloca cerca del espejo de prueba [10]. En procedimientos más recientes, la prueba por pantallas nulas es un método geométrico para evaluar sistemas ópticos. Con el conocimiento a priori de los parámetros de diseño de dicho sistema, se calcula un patrón de manchas o curvas no uniformes, que después de pasar por el sistema óptico generen un patrón predefinido en el plano de detección. Si el sistema óptico no presenta imperfecciones y el arreglo experimental está alineado de manera correcta, las diferencias entre el patrón esperado y la fotografía grabada adecuadamente en el plano de detección serán nulas. De otro modo, las diferencias estarán asociadas a las imperfecciones en el sistema óptico o desalineaciones. El sistema óptico bajo prueba puede ser evaluado tanto por reflexión como por refracción [11-13].

En este trabajo se retomó el diseño de pantallas nulas, similar al reportado en [14], a partir del procesamiento de imágenes de un retrato fotográfico que definirá un conjunto de puntos distribuidos no uniformemente, lo cuál da forma al patrón predefinido. Este método abre posibilidades de exploración artística, ya que a partir de una fotografía se pueden obtener patrones para ser observados bajo un proceso de formación y deformación de la imagen en diferentes planos de detección. Con esto, se propone la construcción de nuevos modelos de representación en el arte y, en específico, se propone el uso de este tipo de imágenes en el diseño de piezas inmersivas. La noción de un lenguaje inmersivo en el arte se explica a partir de la apropiación de un espacio específico que se transforma con imágenes, para simular un mundo artificial tridimensional, donde el observador se sumerge para vivir una experiencia visual envolvente y donde puede moverse e interactuar con elementos a su alcance [15]. En las piezas de arte inmersivas lo perceptible cambia de acuerdo a los movimientos de las personas y están diseñadas para tener diferentes grados de interacción por parte del público.

Para la construcción de estas experiencias existen varias tecnolog Ãas, a la fecha se han realizado estudios precisos [16-18], que desarrollan de manera amplia los procesos referentes a la Realidad Virtual (VR) y la denominada Realidad Mixta (MR), dentro de la cual hallamos la Realidad Aumentada (AR) y la Virtualidad Aumentada (AV), identificadas ambas por mezclar imágenes reales con imágenes generadas por computadora [19]. La Realidad Virtual excluye por completo el espacio físico y sumerge al público en una realidad construida digitalmente, mientras que otras técnicas se benefician del espacio real para crear la inmersión. El uso de estos mecanismos, que hacen referencia a la manera de experimentar un entorno hecho con computadora, deviene en una experiencia totalmente artificial y ficticia [20], consecuencia de un proceso de creación digital, en el que las percepciones del público se apartan totalmente de su mundo real [21].

Actualmente existen múltiples aplicaciones de lo inmersivo. En modelos productivos e industriales, juegos, educación, medicina, cine, música, turismo, literatura y artes visuales. En este terreno se pueden mencionar algunos artistas como Joanie Lemercier, quien trabaja con piezas y ambientaciones capaces de alterar la manera en que percibimos la realidad. Un artista francés, Vincent Houze, utiliza técnicas de gráficos por computadora para crear arte interactivo, presentaciones e instalaciones multimedia a gran escala. Otros referentes funcionales son el colectivo japonés teamLab con sus piezas de efecto inmersivo, o el colectivo de Londres, Marshmallow Laser Feast quienes trabajan especialmente con la Realidad Virtual y experiencias VR sincronizadas. Otros artistas contemporáneos como el turco Can Buyukberber emplean ambas tecnologías.

En el ámbito científico existen investigaciones previas que implican la formación de imágenes en cáusticas, entre ellas también retratos fotográficos, a partir de la optimización geométrica de superficies reflejantes o refractantes en donde se generan patrones para proyectar una forma deseada. Por ejemplo, Schwartzburg et al [22] desarrollaron un método con el que es posible diseñar superficies a través del trazo inverso en cáusticas, a partir de un algoritmo computacional, ayudando a expandir significativamente las posibilidades creativas utilizando la óptica de cáusticas en una variedad de aplicaciones como diseño de interiores, iluminación, arquitectura o arte. A diferencia de los métodos mencionados, donde las imágenes son generadas en su totalidad con computadora, la propuesta de este trabajo es construir imágenes a partir del análisis matemático de un retrato y, con el método de pantallas nulas por refracción, registrar el proceso de formación de imágenes para distintos planos de detección en tiempo real con el uso de un sensor CCD. Este es un método hasta ahora no explorado en las artes y un experimento realizado por primera vez con una fotografía en el grupo de investigación de Metrología óptica del ICAT, UNAM.

Las imágenes capturadas en movimiento tienen una estética particular y están realizadas para dar forma a una pieza de arte, que igualmente pueda ser causante de experiencias visuales envolventes, por medio de varias salidas de proyección sobre superficies que aporten tridimensionalidad a la pieza, que faciliten la movilidad y participación del espectador. Con esta técnica se establece una nueva manera de diseñar y formar imágenes a partir de un retrato fotográfico y utilizando el método de pantallas nulas, se coloca el sensor CCD dentro de la región de la cáustica, donde hasta tres imágenes provenientes de distintas zonas de la lente asférica se fusionan en el mismo espacio [14], siendo un nuevo método que se inscribe sobre la línea de los nuevos modelos de investigación tecno-científica [23-25] en la práctica artística. No obstante se hayan publicado procesos similares de proyección de imágenes, nuestro método para trabajar con un retrato fotográfico considerando colocar el plano de detección dentro de región de la cáustica muestra que comparado 


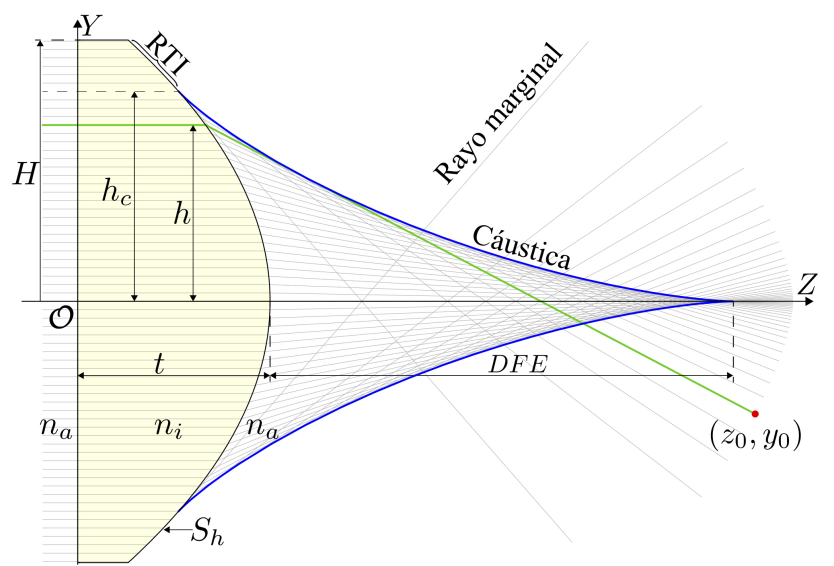

FIGURE 1. Geometría para el trazo exacto de rayos y cáustica en una lente asférica plano-convexa, donde se incluyen los parámetros involucrados en el proceso de refracción.

con las referencias anteriores, todos estos métodos son ampliamente disímiles.

\section{Teoría}

Siguiendo la geometría de la Fig. 1, ubicamos el origen de coordenadas en el vértice de la primer superficie, se considera el plano $Y-Z$ como el plano de incidencia, que es una sección transversal de la lente asférica en su configuración plano-convexa, con simetría de revolución alrededor del eje $\mathrm{Z}$ y se hace incidir un frente de onda plano que viaja de izquierda a derecha.

La lente tiene una apertura $2 H$, un índice de refracción $n_{i}$, y está inmersa en un medio con índice de refracción $n_{a}$, el frente de onda pasa sin desviarse por la primer superficie y llega a la cara asférica que representamos como

$$
S_{h}=\frac{c h^{2}}{1+\sqrt{1-(k+1) c^{2} h^{2}}}+\sum_{i=1}^{N} A_{2 i} h^{2 i},
$$

donde $c$ representa la curvatura paraxial, que es el inverso del radio de curvatura paraxial $R, k$ es la constante de conicidad, $h$ la altura de incidencia arbitraria para un rayo en la familia de rayos del frente de onda plano y $A_{2 i}$ son los coeficientes de asfericidad que deforman los bordes de la lente asférica. Por medio de la ley de Snell, y después de un análisis geométrico, podemos obtener una ecuación que nos describa la refracción fuera de la superficie como

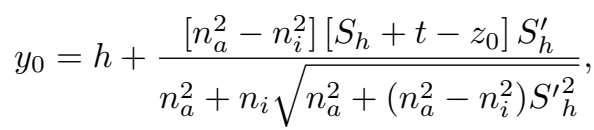

donde $t$ es el espesor axial de la lente, $z_{0}$ y $y_{0}$ representan la posición arbitraria de un rayo fuera de la lente, que incidió a una altura $h$ dada. Dicha altura se verá limitada por el efecto de reflexión total interna (RTI) que se puede calcular igualando a cero y resolviendo para $h$ el radical de la Ec. (2), resultando en $h_{c}$ como la altura máxima a la que un rayo será refractado fuera de la lente, este rayo recibe el nombre de rayo marginal. Es importante mencionar que $z_{0}$, será la posición donde se colocará el sensor CCD a lo largo del eje óptico, y el valor $y_{0}$ formará parte del contorno de la imagen predefinida en el plano de detección. Utilizando el método de las envolventes calculamos la ecuación que representa la superficie cáustica por refracción escrita en forma paramétrica como

$$
\begin{aligned}
y_{c}(h) & =h-\frac{\left[n_{a}^{2}+\left(n_{a}^{2}-n_{i}^{2}\right) S_{h}^{\prime 2}\right] S_{h}^{\prime}}{n_{a}^{2} S_{h}^{\prime \prime}}, \\
z_{c}(h) & =t+S_{h}+\frac{\left[n_{a}^{2}+\left(n_{a}^{2}-n_{i}^{2}\right){S^{\prime}}_{h}^{2}\right]}{n_{a}^{2}\left(n_{a}^{2}-n_{i}^{2}\right) S_{h}^{\prime \prime}} \\
& +\frac{\left[n_{a}^{2}+n_{i} \sqrt{n_{a}^{2}+\left(n_{a}^{2}-n_{i}^{2}\right) S^{\prime 2}}\right]}{n_{a}^{2}\left(n_{a}^{2}-n_{i}^{2}\right) S_{h}^{\prime \prime}},
\end{aligned}
$$

donde $S_{h}^{\prime}$ y $S_{h}^{\prime \prime}$ representan la primera y la segunda derivada de la Ec. (1) con respecto al parámetro $h$. Esta ecuación representa la envolvente de todos los rayos refractados fuera de la lente asférica. Si evaluamos para $h=0$ obtenemos la distancia focal efectiva (DFE).
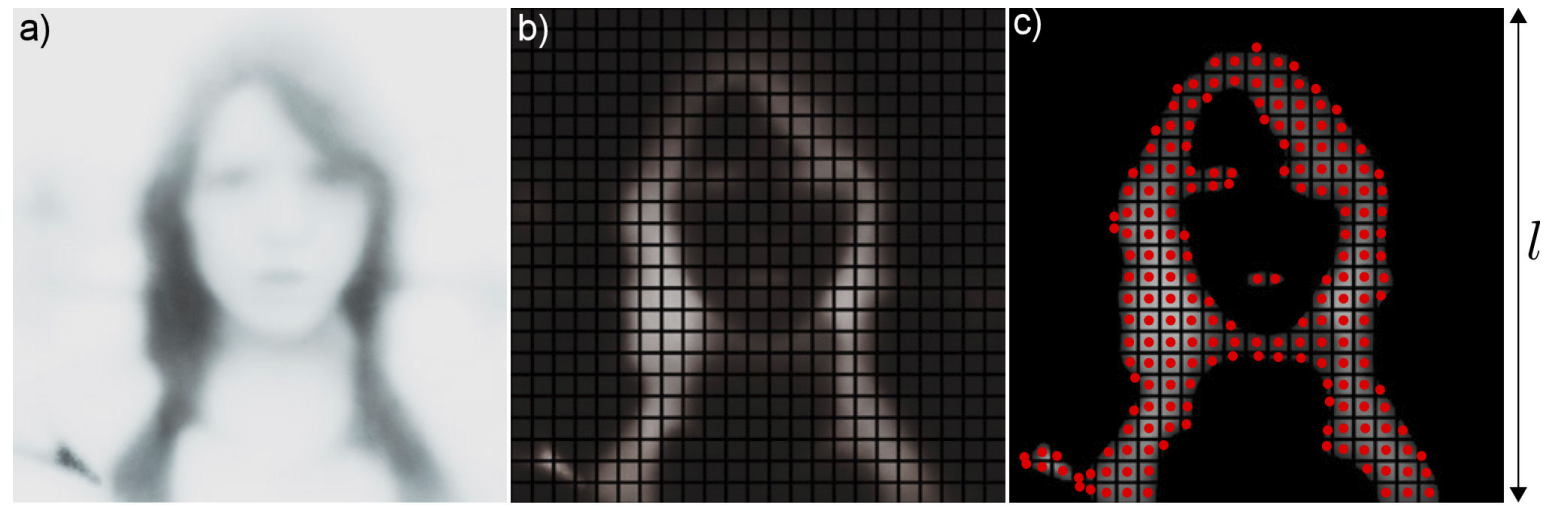

FIGURE 2. a) Retrato original en escala de grises. b) Cuadrícula sobrepuesta, la cantidad de cuadrados varía según el resultado esperado. c) Centroides en rojo para cada cuadrado, calculados por procesamiento de imágenes. 


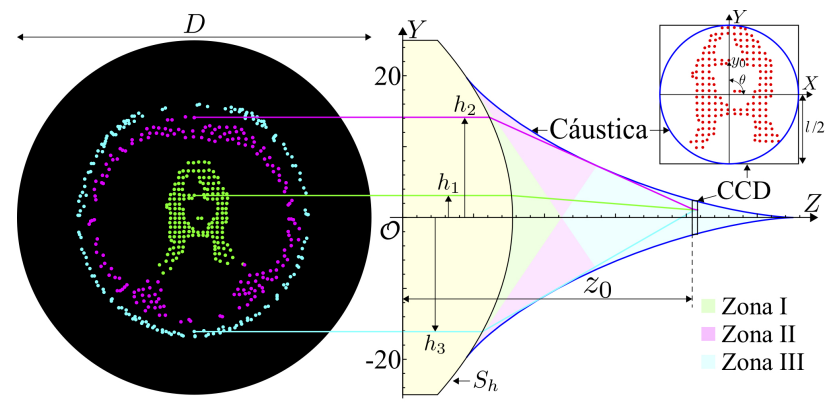

FIGURE 3. Geometría para la pantalla nula, proceso de intersección de rayos en la cáustica y patrón esperado en el CCD. Se pueden apreciar también las zonas de intersección de rayos dentro de la cáustica.

\section{Pantallas nulas a partir de una imagen fo- tográfica}

Como se mencionó anteriormente, para utilizar el método de pantallas nulas se necesita diseñar un patrón predefinido que se formará en el plano de detección, en este trabajo dicho patrón se trabajó a partir de una imagen fotográfica [26] donde aparece un rostro. Teniendo como base la Fig. 2a), se le sobrepone una rejilla cuadriculada de frecuencia variable, en este caso utilizamos $100 \times 100$ cuadrados, resultando el arreglo de la Fig. 2b), a esta imagen se le calcularon los centroides para cada cuadrado inscrito, similar al reportado en [27], resultando un mapa de puntos como se aprecia en la Fig. 2c), a la cual se le hace un escalamiento para que coincida con el lado menor del sensor CCD a utilizar, con medidas $l \times L=4.7616 \times 5.952 \mathrm{~mm}$ y $1024 \times 1280$ ppx. El eje óptico pasa por el centro del sensor CCD, por lo cual cada centroide está a una distancia $y_{0}$ del centro del sensor y a un ángulo $\theta$.

El diseño de esta pantalla se basa en el conocimiento de la superficie cáustica por refracción o diacáustica. Como es bien sabido, la prueba de un sistema óptico se realiza mejor si no se necesitan elementos ópticos adicionales [28], y es importante mencionar que para este trabajo se utilizó solamente un sensor CCD como plano de detección reduciendo los costos de reproducibilidad del arreglo experimental. Con el fin de obtener fotografías con intensidad uniforme, se coloca el plano de detección dentro de la cáustica, aunado al efecto de fusión de patrones que podrá ser manipulado para el espectador, para ello se utiliza la Ec. (3). Por métodos numéricos se calcula una distancia $z_{c}$ a la cual $y_{c}=l$. En la Ec. (2) sustituimos $z_{0}=z_{c}$ con cada $y_{0}$ para cada uno de los centroides obtenidos como se muestra en la Fig. 3, y resolviendo para $h$ obtenemos múltiples soluciones de acuerdo a las zonas de la cáustica. Debido a que estamos en la zona III, obtenemos tres diferentes posiciones para el rayo que entra y convergen en un solo punto, mismas que se rotan a su ángulo $\theta$ correspondiente para formar la pantalla nula de la Fig. 3. Como se puede observar, los tres patrones de puntos diferenciados por colores forman pantallas nulas complementarias, que en el plano de detección o CCD formarán un único patrón de intensidad uniforme. Es importante mencionar que los tres grupos de puntos formarán el patrón predefinido, aún si se evalúan de forma separada.

TABLE I. Parámetros para la lente asférica de catálogo.

\begin{tabular}{ccc}
\hline$n_{a}$ & $n_{i}$ & $R$ \\
\hline 1 & 1.7845 & $-31.075 \mathrm{~mm}$ \\
$k$ & $D$ & $t$ \\
-0.744 & 50 & $15.5 \mathrm{~mm}$ \\
$D F E$ & $\lambda$ & $t$ \\
55.11 & $633 \mathrm{~nm}$ & $15.5 \mathrm{~mm}$ \\
$A_{4}$ & $A_{6}$ & $A_{8}$ \\
$-4.3665221 \times 10^{-7}$ & $2.2713591 \times 10^{-10}$ & $1.7042174 \times 10^{-13}$ \\
$A_{10}$ & $A_{12}$ & $A_{14}$ \\
$3.6809344 \times 10^{-17}$ & $-8.9443459 \times 10^{-21}$ & $-1.8501188 \times 10^{-23}$ \\
\hline
\end{tabular}

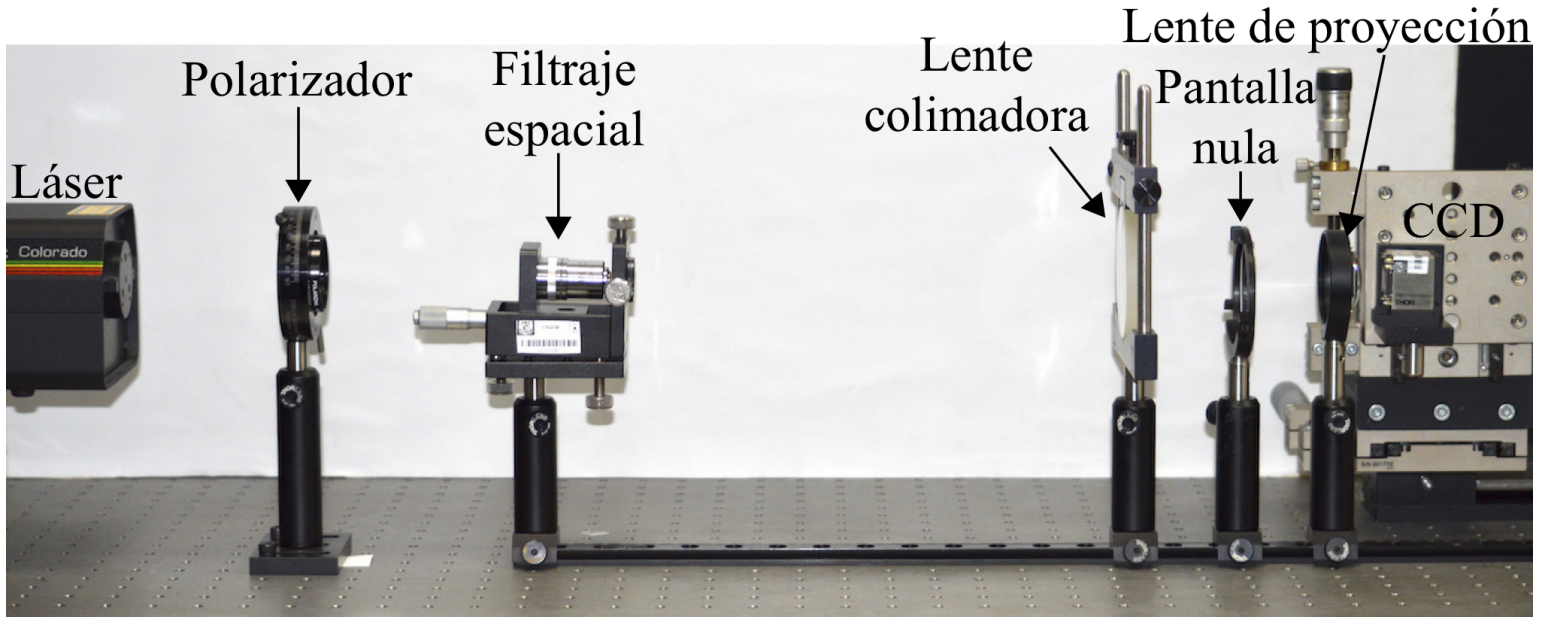

FIGURE 4. Montaje en laboratorio para pieza inmersiva con capacidades de manipulación para el observador. 


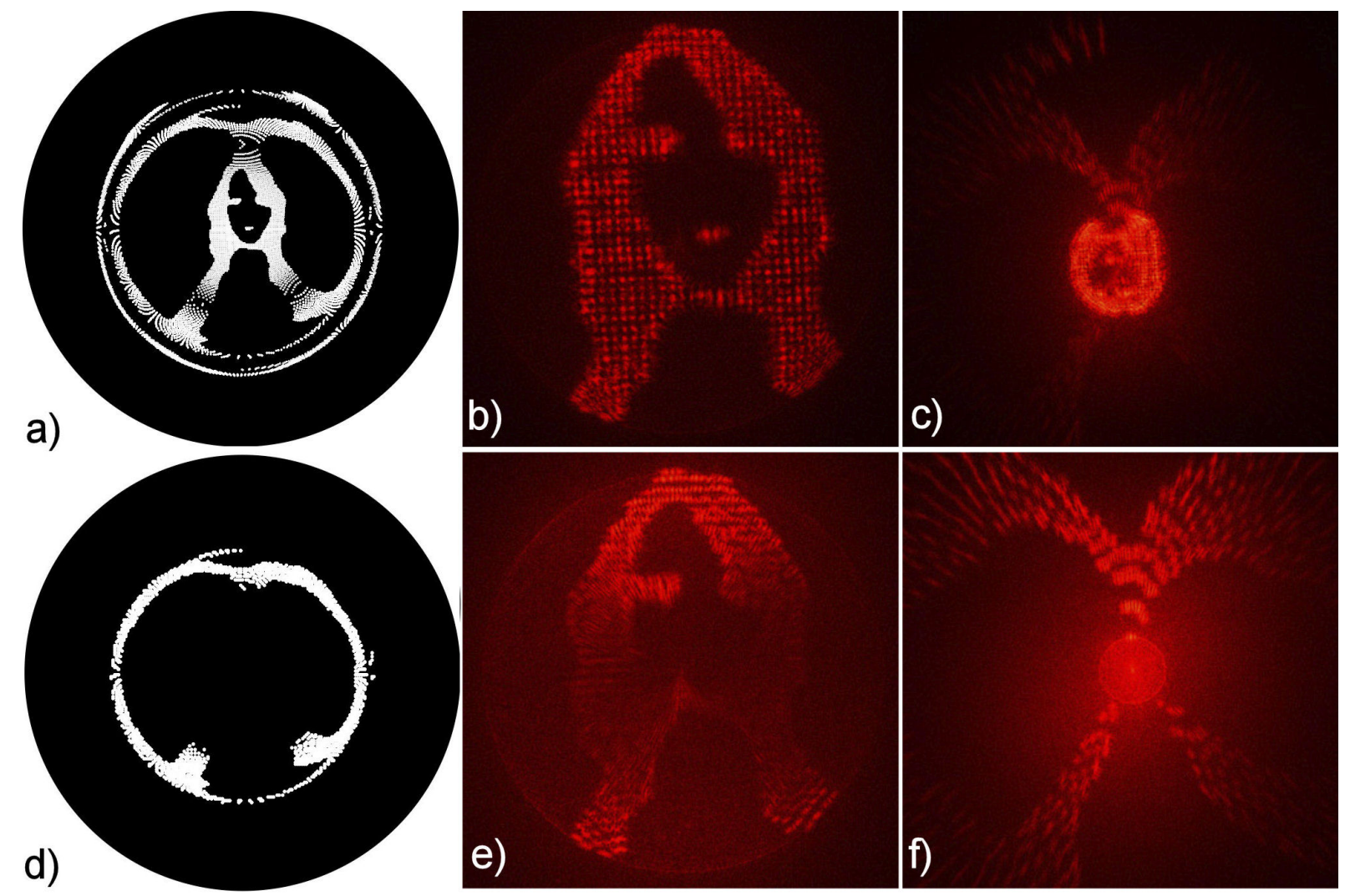

FIgURE 5. a) Pantalla nula con tres soluciones complementarias. b) Fotografía en el plano de detección de diseño. c) Fotografía fuera del plano de detección de diseño mostrando falta de uniformidad en la intensidad. d) Pantalla nula con soluciones exteriores. e) Fotografía tomada en el plano predefinido mostrando una formación equivalente a las soluciones conjuntas. f) Fotografía fuera del plano predefinido para la pantalla nula exterior, mostrando una clara deformación de la imagen.

\section{Implementación de la pieza inmersiva en laboratorio}

Para este ejercicio se diseñaron pantallas nulas para trabajar con la lente asférica cuyas características técnicas se encuentran en la Tabla I, se procede entonces a implementarlas en una prototipo controlado de pieza inmersiva en laboratorio con el fin de verificar que el cálculo es correcto, así como experimentar la manipulación de imágenes en diferentes planos de detección. Este montaje experimental se llevó a cabo en el laboratorio de Pruebas ópticas del ICAT-UNAM. Para ello se utilizó un láser polarizado Helio-Neón multilínea con cinco longitudes de onda $(543 \mathrm{~nm}, 594 \mathrm{~nm}, 604 \mathrm{~nm}, 612 \mathrm{~nm}$ y $633 \mathrm{~nm}$ ) modelo 30602 de Research Electro-Optics, un polarizador Polaroid, una montura para filtraje espacial Edmund Optics con un objetivo de microscopio Edmund Optics de $20 \times$ y un pinhole de $20 \mu \mathrm{m}$, un doblete acromático con una distancia focal efectiva de $400 \mathrm{~mm}$ y $75 \mathrm{~mm}$ de diámetro para generar el frente de onda plano y una cámara con el sensor CCD descrito anteriormente. El montaje se coloca sobre una mesa holográfica como se muestra en la Fig. 4.

Finalmente, se graban la imágenes con un sensor CCD que nos proveerá como medio de transmisión a proyecciones digitales. El diseño de las imágenes supone que las pantallas nulas están impresas en acetato y que se colocan frente a una lente asférica rápida $(F / \#<1)$, un frente de onda plano monocromático incide en la pantalla y en la primera superficie de la lente, entonces por el proceso de refracción, al salir por la segunda superficie formará las imágenes que componen la pieza. Obtuvimos tres pantallas nulas complementarias con una cuadrícula de $100 \times 100$. Los resultado de las imágenes en la recuperación del retrato fotográfico se obtuvieron a partir de dos variantes en pantallas nulas como se puede observar en la Fig. 5a) que contiene las tres soluciones complementarias y la Fig. 5d) que contiene únicamente la solución dos, esto quiere decir únicamente las $h_{2}$. En las Fig. $5 b$ ) y Fig. 5e) la posición del sensor $\mathrm{CCD}=z_{0}$, por lo tanto, es la imagen esperada y capturada en la región de la cáustica. Para las Fig. 5c) y Fig. 5f) la posición corresponde a la captura de imagen $z=50 \mathrm{~mm}$, esto es, cercana al foco de la lente, mostrando una clara deformación de la imagen al punto de ser irreconocible.

El registro en movimiento presenta variantes en la imagen de acuerdo a la distancia entre los elementos del sistema óptico. En la Fig. 6 se observa una breve secuencia de imágenes en diferentes planos de detección dentro de la región de la cáustica que muestran el comportamiento de la formación de la imagen para dar lugar a una inmersión en la pieza artística. 

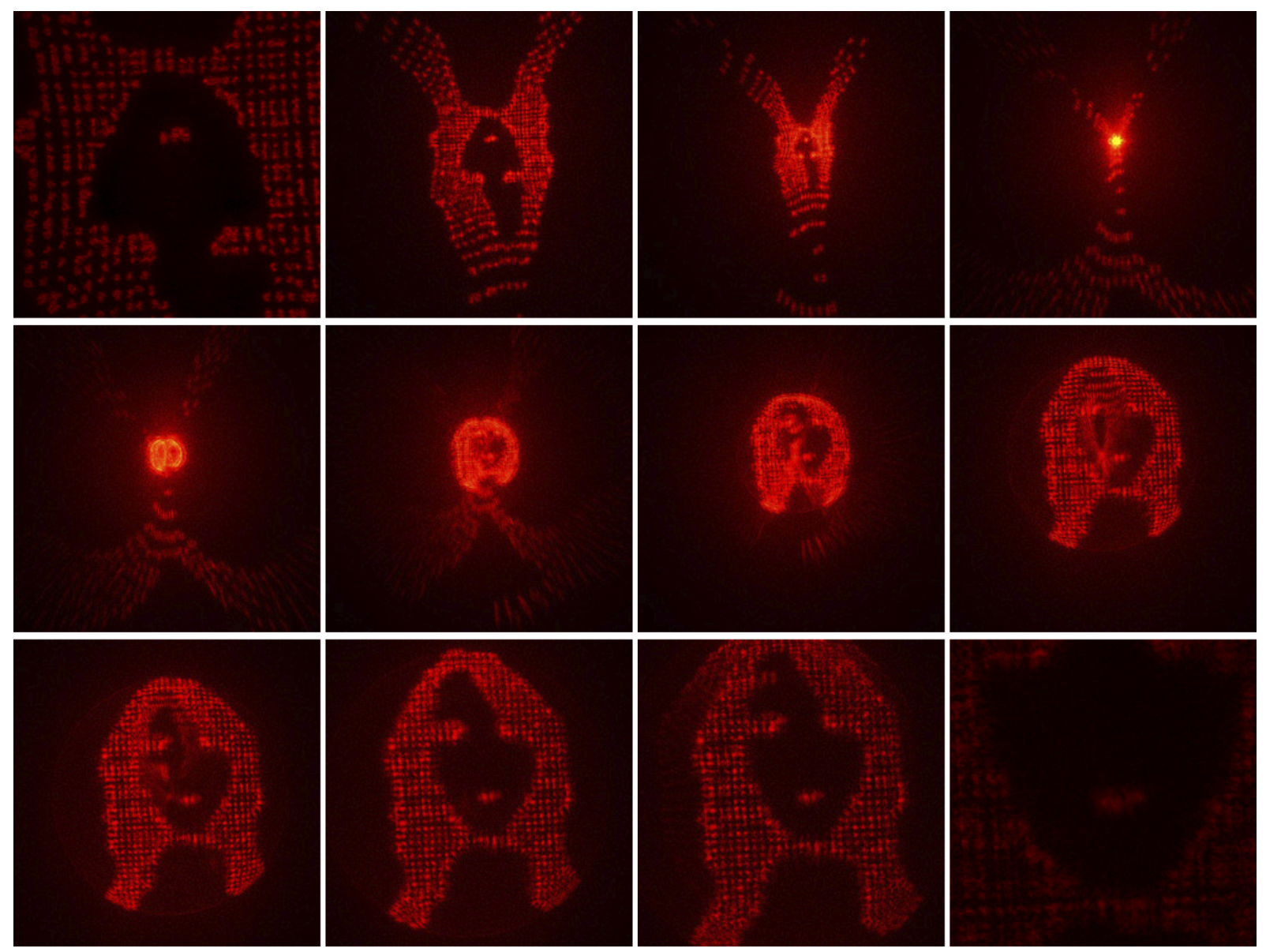

FIGURE 6. Secuencia de fotografías para la pantalla nula de la Fig. 5a) empezando en $z=55 \mathrm{~mm}$ y acercando el sensor CCD hacia el vértice de la segunda superficie dentro de la región de la cáustica.

\section{Conclusiones}

Con el diseño de pantallas nulas por refracción a partir de un retrato fotográfico y la alineación de sistemas ópticos, a los que se aplican variables en posicionamiento y alineación, se pueden generar patrones para imágenes fijas y en movimiento que se pueden utilizar en piezas de arte inmersivas. Se pueden utilizar diferentes longitudes de onda y diferentes imágenes para una misma pieza de arte. Se considera que la inmersión depende no solamente de las imágenes que se diseñan, dependen también de la arquitectura del espacio, de los materiales que se utilizan para proyección y en última instancia, de fuentes de sonido diseñadas en 3D para lograr la total inmersión de las piezas. El método que presentamos, a diferencia de los procedimientos utilizados para crear contenidos de piezas inmersivas y de las técnicas para controlar patrones de fotografías a partir de superficies cáusticas, constituye una diferencia metodológica axiomática. Es un método que se explora por primera vez en el área de las artes y de la ciencia, terreno en el que se trabajan las pantallas nulas como arreglos de patrones, con el fin de medir cualidades de una superficie óptica y no con fotografías, lo cual abre posibilidades discursivas y de producción en proyectos de investigación de orden multidisciplinario donde convergen arte, ciencia y tecnología.

\section{Acknowledgments}

Este trabajo se ha desarrollado como parte del proyecto de investigación doctoral "Física óptica aplicada al arte: una propuesta metodológica", financiado por la Universidad Nacional Autónoma de México, a través del Programa de Artes y Diseño (CDMX) y gracias a los estudios realizados con la colaboración del Grupo de investigación de Pruebas ópticas, en el Instituto de Ciencias Aplicadas y Tecnología (ICATUNAM). Con el soporte del Programa de Apoyo a Proyectos de Investigación e Innovación Tecnológica, Universidad Nacional Autónoma de México PAPIIT-UNAM \#IN112618. 
1. O. N. Stavroudis, The Mathematics of Geometrical and Physical Optics 12 (Wiley-VCH Verlag, 2006) Chap. 4, pp. 179-186.

2. M. Avendaño-Alejo, L. Castañeda, and I. Moreno, J. Opt. Soc. Am. A 27 (2010) 2252.

3. M. Avendaño-Alejo, D. G. Utrera, and L. Castañeda, J. Opt. Soc. Am. A 28 (2011) 2619.

4. M. Avendaño-Alejo, M.C. López-Bautista, L. Castañeda, and S. Maca-García, Appl. Opt. 58 (2019) 939.

5. G. Dai, Wavefront optics for vision correction (SPIE Press, 2008) Chap. 3.

6. D. L. Shealy, Optical Engineering 14 (1975).

7. J. A. Lock, C. L. Adler, and E. A. Hovenac, J. Opt. Soc. Am. A 17 (2000) 1846.

8. S. A. Juárez-Reyes et al., J. Opt. Soc. Am. A 31 (2014) 448.

9. D. Malacara and Z. Malacara, Handbook of lens design (Marcel Dekker Inc., 1994).

10. D. Malacara, Optical Shop Testing, 3rd ed. (John Wiley and Sons, New Jersey, 2007).

11. A. C. Davila, A. C. Rodriguez, and O. C. Nunez, Appl. Opt. 29 (1990) 4618.

12. D. Aguirre-Aguirre, M. Campos-García, R. Díaz-Uribe, and B. Villalobos-Mendoza, Applied Optics 57 (2018 10230.

13. R. Díaz-Uribe and M. Campos-García, Appl. Opt. 39 (2000) 2670.

14. G. Castillo-Santiago, D. Castán-Ricaño, M. Avendaño- Alejo, L. Castañeda, and R. Díaz-Uribe, Opt. Express 24 (2016) 19405.

15. J. Manuel-Menéndez and D. Jiménez-Bermejo, Creatividad inmersiva, inmersividad creativa, Anuario AC/E de cultura digital, 17 (2018).

16. M. Slater, B. Spanlang, M. V. Sanchez-Vives, and O. Blanke, PLOS ONE 5 (2010) 1.
17. S. Aukstakalnis and D. Blatner, Silicon Mirage; The Art and Science of Virtual Reality (Peachpit Press, Berkeley, CA, USA, 1992).

18. J. Galán Serrano, C. Garca-García, and F. Felip Miralles, Revista de Expresión Gráfica en la Edificación 10 (2018) 1.

19. J. Lanier, Virtual reality: The promise of the future, Interactive Learning International 8 (1992).

20. P. Lévy, ¿Que es lo virtual? (Ediciones Paidós Ibérica, 1999).

21. F. Popper, From Technological to Virtual Art (The MIT Press, 2006).

22. Y. Schwartzburg, R. Testuz, A. Tagliasacchi, and M. Pauly, ACM Trans. Graph. 33 (2014) 74: 1 Proc. SIGGRAPH 2014.

23. S. Veciana-Schultheiss, RESEARCH ARTS: La intersección arte, ciencia y tecnología como campo de conocimiento y de acción, Tesis doctoral, Universitat de Barcelona (2004).

24. H. Wengrower, Arteterapia. Papeles De Arteterapia Y educación artística Para La inclusión Social 7 (2012) 41-56.

https://revistas.ucm.es/index.php/ARTE/article/view/40760

25. M. Finckh, H. Dammertz, and H. P. A. Lensch, Geometry construction from caustic images, in Computer Vision ECCV 2010, edited by K. Daniilidis, P. Maragos, and N. Paragios (Springer Berlin Heidelberg, Berlin, Heidelberg, 2010) pp. 464-477.

26. E. Vázquez-Navarrete, Física óptica aplicada al arte: una propuesta metodologica, Tesis doctoral, Universidad Nacional Autónoma de México (2020).

27. G. Castillo-Santiago, Evaluación de lentes implementando una prueba geométrica dentro de la cáustica, Tesis doctoral, Universidad Nacional Autónoma de México (2019).

28. A. Cordero-Davila, A. Cornejo-Rodriguez, and O. C.-N. nez, Appl. Opt. 31 (1992) 2370. 